\title{
CONF-950793--46
}

UCRL-JC-120330

PREPRINT

\section{Stimulated Dual-Band Infrared Computed Tomography: A Tool to Inspect the Aging Infrastructure}

\author{
N. K. Del Grande and P. F. Durbin
}

This paper was prepared for submittal to the SPIE Optical Science, Engineering, and Instrumentation Conference San Diego, CA

July 9-14, 1995

June 27, 1995

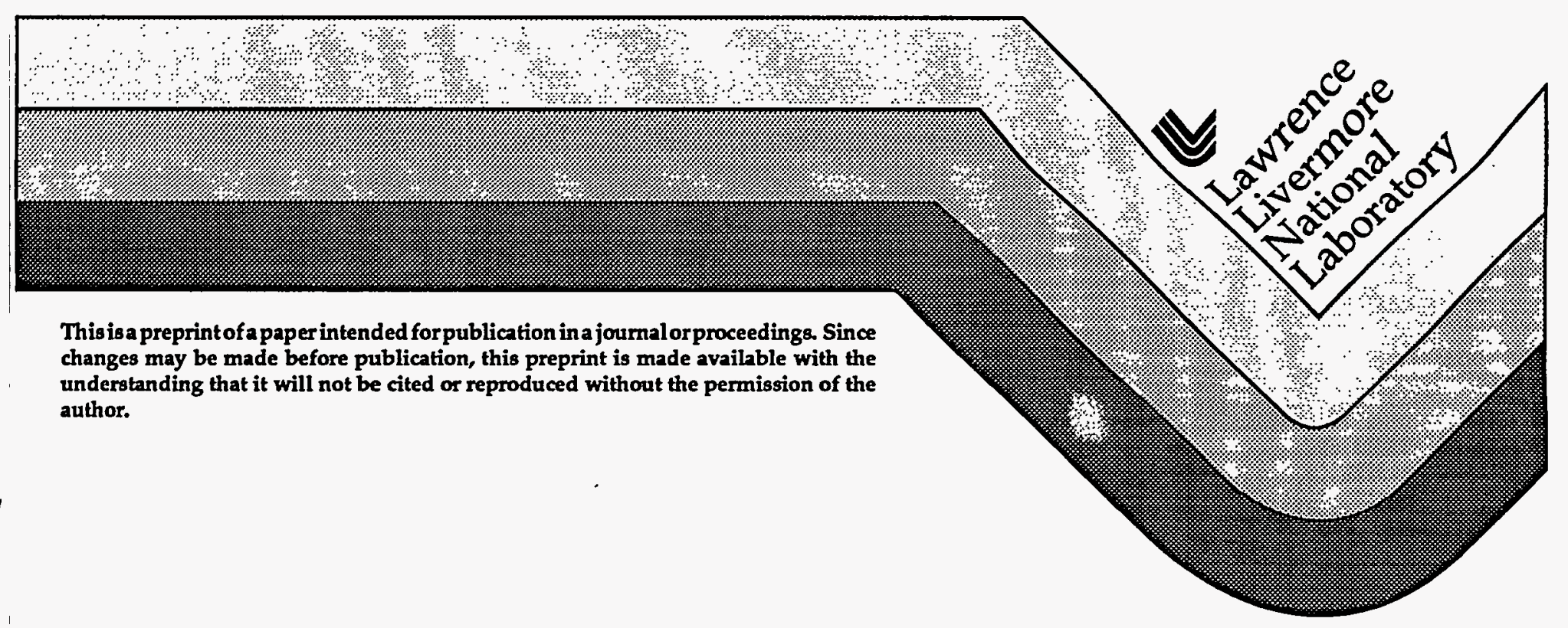




\section{DISCIAIMER}

This document was prepared as an account of work sponsored by an agency of the United States Government. Neither the United States Government nor the University of California nor any of their employees, makes any warranty, express or implied, or assumes any legal liability or responsibility for the accuracy, completeness, or usefulness of any information, apparatus, product, or process disclosed, or represents that its use would not infringe privately owned rights. Reference herein to any specific commercial product, process, or service by trade name, trademark, manufacturer, or other wise, does not necessarily constitute or imply its endorsement, recommendation, or favoring by the United States Government or the University of California. The views and opinions of authors expressed herein do not necessarily state or reflect those of the United States Government or the University of California, and shall not be used for advertising or product endorsement purposes. 


\section{DISCLAIMER}

Portions of this document may be illegible in electronic image products. Images are produced from the best available original document. 
Stimulated dual-band infrared computed tomography: a tool to inspect the aging infrastructure

Nancy K. Del Grande and Philip F. Durbin

Lawrence Livermore National Laboratory, P.O. Box 808, Livermore CA 94551

\begin{abstract}
We have developed stimulated dual-band infrared (IR) computed tomography as a tool to inspect the aging infrastructure. Our system has the potential to locate and quantify structural damage within airframes and bridge decks. Typically, dual-band IR detection methods improve the signal-to-noise ratio by a factor of ten, compared to single-band $\mathbb{R}$ detection methods. We conducted a demonstration at Boeing using a uniform pulsed-heat source to stimulate $\mathbb{R}$ images of hidden defects in the 727 fuselage. Our dual-band $\mathbb{R}$ camera and image processing system produced temperature, thermal inertia, and cooling-rate maps. In combination, these maps characterized the defect site, size, depth, thickness and type. We quantified the percent metal loss from corrosion above a threshold of $5 \%$, with overall uncertainties of $3 \%$. Also, we conducted a feasibility study of dual-band IR thermal imaging for bridge deck inspections. We determined the sites and relative concrete displacement of 2-in. and 4-in. deep delaminations from thin styrofoam implants in asphalt-covered concrete slabs. We demonstrated the value of dual-band IR computed tomography to quantify structural damage within flash-heated airframes and naturally-heated bridge decks.
\end{abstract}

Keywords: dual-band infrared imaging, infrared computed tomography, thermal nondestructive evaluation

\title{
1.0 INTRODUCTION
}

\subsection{Conventional thermography}

Recent applications of thermography include nondestructive inspection and evaluation (NDI and NDE) of airframes, composites, and aerospace structures. Infrared imaging and detection has the potential of rapidly inspecting large areas at video frame rates (30 frames per second) to provide an early warning of subsurface defects, e.g., corrosion thinning, sites with poor adhesive bonding (unbonds), voids, inserts, and delaminations. Using single-band infrared (SBIR) imaging methods, scientists have successfully depicted the sites of subsurface defects in manmade structures. $1-5$

Conventional SBIR imaging methods have not been able to classify defect types. They have not successfully distinguished between major defects that affect the mechanical integrity of large structures, e.g., more than $10 \%$ corrosion thickness reduction, and minor defects that do not warrant costly repairs, e.g., ripples, sealant globs, uneven paint, stains, tape markers, scratches, dents, and insulation wads attached to the interior of the aircraft fuselage. A recent round-robin investigation of commercial NDI equipment used to detect hidden corrosion on U.S. Air Force aircraft indicated that false detection of corrosion results in unnecessary and destructive exploratory maintenance. ${ }^{6}$

\subsection{Thermography needed to image anomalous structural heat flows}

Lawrence Livermore National Laboratory (LLNL) has pioneered an emissivity-corrected, dual-band infrared (DBIR) method, which images anomalous heat flows from buried objects and structural defects. ${ }^{7}$ The DBIR method quantifies corrosion (percent metal-thickness reduction) damage within flash-heated metal and naturally-heated concrete structures. ${ }^{8-17}$ Typically, the DBIR method provides from five-to-ten-times improved defect signal-to-noise ratios, and better interpretability, compared to SBIR methods. Improved temperature contrast, clutter removal, and quantification of material losses are features of the DBIR method that clarify interpretation of defect sites by classifying defect types and eliminating false-defect calls.

\subsection{Rationale for precise, emissivity-corrected, thermal imaging}

We discuss an adaptation of the DBIR thermal imaging method for aircraft and concrete bridge deck inspections. ${ }^{7}$ To this end, we image two simultaneously-recorded infrared (IR) wavelength intervals at 3-5 $\mu \mathrm{m}$ and 8-12 $\mu \mathrm{m}$. We make use of a property of Planck's Radiation law, that near $288 \mathrm{~K}\left(15^{\circ} \mathrm{C}\right)$, the DBIR (radiant emittance) signal intensities vary as the emissivity times absolute temperature $(T)$ to the power $(50 / \lambda)$ where $\lambda$ is the wavelength in microns. ${ }^{18}$

This expression is based on a power-series expansion of Planck's radiation law which provides a convenient approximation (at wavelength intervals centered near $5 \mu \mathrm{m}$ and $10 \mu \mathrm{m}$ ). The signals near $5 \mu \mathrm{m}$ vary as the tenth power of temperature, $T$, whereas the signals near $10 \mu \mathrm{m}$ vary as the fifth power of temperature, T. By taking the appropriate DBIR image ratios, we produce images of high-contrast temperature $\left(\mathrm{T}^{5}\right)$ maps and surface emissivity-noise $(\mathrm{E})$ maps, where: 


$$
\begin{gathered}
\left(\mathrm{T} / \mathrm{T}_{\mathrm{av}}\right)^{5}=\left(\mathrm{S} / \mathrm{S}_{\mathrm{av}}\right) /\left(\mathrm{L} / \mathrm{L}_{\mathrm{av}}\right) \\
E=\left(\mathrm{L} / \mathrm{L}_{\mathrm{av}}\right)^{2} /\left(\mathrm{S} / \mathrm{S}_{\mathrm{av}}\right)
\end{gathered}
$$

In Eqs (1) and (2), $S$ is the short-wavelength intensity signal, Sav is the average value of the pixels in $S, L$ is the long wavelength intensity signal, and Lav is the average value of the pixels in L.

We use DBIR image ratios, from DBIR cameras which scan targets at infrared wavelengths of 3-5 $\mu \mathrm{m}$ and 8-12 $\mu \mathrm{m}$, to enhance surface temperature contrast and remove the mask of surface emissivity noise. This clarifies interpretation of subtle heat flow anomalies associated with hidden structural defects in multi-layered metal and concrete structures.

\subsection{Pulsed thermal imaging}

During 1994, we developed a field-portable DBIR prototype system for non-destructive inspection (NDI) of flash-heated aircraft structures for the Federal Aviation Administration Technical Center. The DBIR prototype system has a unique combination of spatial $(0.5 \mathrm{~mm})$, thermal $\left(0 .{ }^{\circ} \mathrm{C}\right)$, spectral $(3-5 \mu \mathrm{m}$ and $8-12 \mu \mathrm{m})$, and temporal $(0.5 \mathrm{~ms}$ per line) resolution. Spatial, thermal, temporal and spectral resolution are exploited to clarify interpretation of hidden structural defects in pulsed-thermal NDE.

\subsection{Thermal inertia maps}

Thermal inertia is a measure of the bulk thermal properties for the target material. We developed thermal inertia (or effusivity) maps to characterize structural defects depicted by pulsed thermal imaging. Thermal inertia maps have been used previously for other applications. ${ }^{19,20}$ We solve the heat transfer equation for a thick target with an instantaneous surface heat flux: ${ }^{21}$

$$
T(x, t)=\frac{q}{\sqrt{4 \pi k \rho c t}} \exp \left(-\frac{x^{2}}{4 \alpha t}\right)
$$

where $T$ is temperature, $x$ is the distance from the surface, $\mathrm{k}$ is thermal conductivity, $\rho$ is density, $\mathrm{c}$ is heat capacity, $\alpha$ is thermal diffusivity, $t$ is time and $q$ is the surface heat flux. For a semi-infinite solid approximation, the surface temperature is proportional to the inverse square root of time. In practice, we map the fuselage composite thermal inertia, (krc) ${ }^{1 / 2}$, based on the (inverse) slope of the surface temperature versus the inverse square root of time.

\subsection{Timegram cooling-rate maps}

The timegram records the dynamics of flash-heated linescan profiles across the target. The timegram has time increasing downward, along the vertical axis, the target profile positioned along the horizontal axis, and the target cooling-rate signature measured by color-coded temperature differences. Algorithms generate co-registered thermal, timegram cooling-rate, and thermal inertia maps which clarify interpretation of structural defects and eliminate false (corrosion-loss) defects. Using pulsed-thermal imaging, we characterize structural defects by their location, depth and the degree to which their cooling-rate signatures differ from ambient for the host-material.

\subsection{Detecting defect sites, sizes and depths in three dimensional space}

Using VIEW image processing macros, we developed algorithms for infrared computed tomography (IRCT). We produced coregistered images of emissivity-corrected temperature, thermal inertia and timegram cooling-rate maps. Using these maps, we inferred the defect type, site, size, material-loss and depth. The heat flow anomalies generated by a $4.2 \mathrm{~ms}$ heat flash have thermal signatures which characterize the target physical properties, such as temperature, cooling rate, and thermal inertia. These thermal signatures differ at sites where the multi-layered structures are defective.

\subsection{Interpretability of structural defects}

We addressed the important issue of interpretability. False (corrosion-loss) defects are generated quite frequently from sealant thickness variations and production ripples. Corrections made with dual-band IRCT methods clarify interpretation of materialloss defects from corrosion. Based on the Tinker AFB studies, conventional thermal imaging methods locate about as many 
false as true corrosion-loss defects. For military aircraft, the IRCT method potentially halves the exploratory maintenance repair costs.

We developed algorithms to remove factors which obscur proper identification of airfame corrosion-loss defects. Firstly, typical flashlamp sources produce uneven heat pattems. We correct for this with filters generated by IRCT algorithms which remove the uneven heat source effects for a uniform thickness reference standard. Secondly, emissivity noise from surface clutter (tape marks, dirt, uneven paint, stains, roughness variations) obscures identification of defect sites. Both clutter and defect sites appear on uncorrected thermal maps, while only defect sites appear on corrected thermal maps.

Thirdly, interpreting airframe bulges as "pillowing" from expansion of corrosion by-products is subjective. Visible indicators of surface bulges vary only slightly for different types of material defects (e.g., corrosion by-products, sealant globs, and production ripples). To gain improved precision, definition and interpretability, we measure the dynamic pulsed-thermal timegram and thermal inertia responses.

\subsection{IRCT DEMONSTRATION TO INSPECT THE BOEING 727}

We describe temperature, timegram and thermal inertia maps which clarify interpretation of defects and quantify the percent metal losses from corrosion within the 727 airframe. See Figures 1 and 2.

\subsection{Description of temperature maps}

The temperature maps refer to skin measurements at 0.43 seconds after the flash. They show the various surface temperatures for skin thicknesses of $.063, .070$ and .107 inches, measured with ultrasonic thickness gauges, near S27r at body station 1066. Using the six reference standards, we determined that a typical $1^{\circ} \mathrm{C}$ temperature rise at 0.43 seconds after the flash corresponded to a $12.5 \%$ metal loss for laps and skins ranging in total thickness from .030 to 0.125 inches. The color-coded temperature scale uses a separate color hue to represent a $1^{\circ} \mathrm{C}$ change, and intensity differences to represent $0.1^{\circ} \mathrm{C}$ changes.

\subsection{Description of timegram cooling-rate maps}

The timegram cooling-rate maps show the cooling-rate signatures at 0 to 0.16 seconds after the flash for linescan profiles along S26r and S27r. Metal thinning, from chemical milling, corrosion, or other causes, has a characteristic cooling-rate signature on the timegram map. Thinner skins reach higher peak temperatures, and take longer to cool to the ambient temperature.

\subsection{Description of thermal inertia maps}

The thermal inertia maps show how the near surface structures, when compared to the deeper structures, have varying physical properties. Thermal inertia is the square root of the target conductivity, density, and heat capacity. It is a measure of the resistance to temperature change for bulk materials within the target.

Corrosion by-products have a very different thermal inertia than metal skins. At early times, from 0.1 to 0.4 seconds, the thermal inertia maps depict thermal property differences for near-surface materials, objects, and structures, such as uneven paint, sealant globs, rivets, and skin-corrosion by-products. At later times, the thermal inertia maps characterize corrosion defects, fabrication flaws, substances which impede corrosion within deeper structures, and substances on the inside surface.

\subsection{Thermal NDE results for the Boeing 727 airframe}

The results for the 727 airframe which we inspected at Boeing are shown in Figures 1, and 2. Figure 1 shows the stringer S26r lap splice and the stringer S27r skin temperature maps and timegrams. The temperature map is a composite of eight images, each of which overlapped the adjacent images.

Typical above-ambient temperature variations along the .115-in. thick lap profile at S26r, from body stations 1035 to 1070 , averaged $0.3 \pm 0.2^{\circ} \mathrm{C}$. This is equivalent to the effect of $4 \pm 2$ percent, or .004 -in. \pm .002 -in., corrosion thinning. Clearly, the lap may have had fabrication thickness variations of this order. Apart from the effect of rivets, the lap timegram coolingrate signatures were uncharacteristic of corrosion.

Also shown in Figure 1 are typical above-ambient temperature variations along the .063 -in. skin profile at $S 27 r$, from body stations 1035 to 1070 , where above-ambient temperatures averaged $0.8+0.2^{\circ} \mathrm{C}$. This is equivalent to the effect of $10 \pm 2.5$ 
percent, or .006 -in. \pm .0015 -in., corrosion thinning. The singlc-skin timegram cooling-rate signatures for $527 \mathrm{r}$ were more characteristic of corrosion, especially near body stations 1053 and 1063 where there were, in addition, visible indications of pillowing. Doublers and triplers at S27r body stations 1070 to 1085 produce regions cooler than their surroundings by several degrees Celsius. These regions had cooling-rate signatures unlike the regions without doublers or triplers.

The 727 temperature maps in Figure 2 show .107 in. skins as green, .070 in. skins as yellow and .063 in. skins as red. The thinner skins were chemically milled. Co-positioned doublers, triplers and stiffeners which had a total thickness of about 0.50 in., appeared as blue at $0.43 \mathrm{~s}$ after the flash. The stringer S27r skin thicknesses were measured using an ultrasonic thickness gauge.

Figure 2 also shows the 727 thermal inertia maps for stringer S27r. Thermal inertia is a measure of the target material resistance to temperature change. At early times, from 0.1 to $0.4 \mathrm{~s}$, thermal inertia maps show shallow riveted skins. At late times, from .4 to $.7 \mathrm{~s}$, the thermal inertia maps show the dceper structures such as those used as stiffeners to strengthen Stringer 27r. The S27r skin at body station 1066 was riveted to a deeper structure. By clarifying interpretation, thermal inertia maps eliminate false-defect calls which could lead to costly destructive exploratory maintenance.

\subsection{RESULTS OF FEASIBILITY STUDY FOR BRIDGE DECK INSPECTIONS}

We describe the rationale and image-processing analysis for NDI of known synthetic delaminations, such as thin styrofoam implants, in concrete and asphalt-covered concrete slabs. See Figures 3 and 4.

\subsection{Distinguishing structural defect sites from emissivity noise in concrete structures}

To successfully demonstrate the feasibility of concrete bridge deck inspections, we used emissivity-corrected thermal NDE to clarify the sites of synthetic delaminations within a concrete slab. Our tower-mounted DBIR system simulated the bridge-deck optics. Figure 3 shows the sites of five known 2-inch deep synthetic delaminations in a concrete slab, which were left and right of center. Figure 4 shows the sites of known 2-inch deep, at top left, and 4-inch deep, at top right, synthetic delaminations in an asphalt-covered concrete slab.

\subsection{Enhancing temperature contrast and eliminating emissivity noise}

Using DBIR image ratios, e.g., from DBIR cameras which scan at infrared wavelengths of 3-5 mm and 8-12 mm, we enhanced temperature contrast and removed the mask from surface-emissivity noise. We studied the effects of surface contamination and compositional variations. We placed various objects along the perimeter of the slabs, such as sand, gravel, grease stains, oil spots, metal objects, and lane markers. We developed algorithms to distinguish surface object sites from hidden defect sites.

The use of enhanced temperature-contrast and emissivity-noise maps clarified interpretation of the concrete slab implant sites in Figure 3. The concrete composition, near the slab center and upper left comer, produced a surface which did not behave like an ideal blackbody surface. Consequently there was a non-thermal pattem on the enhanced temperature map. Since this pattem was also on the emissivity-noise map, we knew it was not related to a heat flow anomaly generated by the thin styrofoam implants. The concrete composition at this site had a molecular-stretch resonance at the 8-12 $\mathrm{mm}$ wavelength interval.

\subsection{Processing to remove top-layer temperature gradient}

To clarify interpretation of subtle heat flow anomalies associated with deep delaminations sites, we removed the heat flow anomalies from the asphalt surface layer shown in Figure 4. Density variations over the upper 2-inch layer of pavement, e.g., for unevenly-compacted asphalt, produced a $2{ }^{\circ} \mathrm{C}$ temperature-gradient mask. Using the LLNL/VIEW code, we removed this mask with image processing to depict the deeper (and weaker) $0.6^{\circ} \mathrm{C}$ temperature gradients from the site of the synthetic delamination at a 4 inch depth, top right corner, and at the asphalt-concrete interface, at a 2 inch depth, top left comer.

\section{3.t Follow-on bridge deck inspections from a moving vehicle}

Having achieved all the goals of the feasibility study, we are adapting the emissivity-corrected thermal NDE system, with VIEW image processing, to inspect a concrete bridge deck from a moving vehicle. We will select a bridge deck which is designated for repair so that we can inspect it before and after the repairs have been made. The potential near-term benefits of the emissivity-corrected thermal imaging system are in-service monitoring from a moving vehicle to inspect the structural integrity of the bridge deck. 


\subsection{SUMMARY AND CONCLUSION}

We demonstrated a fast, wide-area, NDI method to quantify aircraft corrosion damage, such as percent metal loss, above a threshold of $5 \%$, with $3 \%$ calibration uncertainties. It has been used successfully to characterize defect types, and their respective depths, in multi-layered composite materials used for wing patches and doublers. The dual-band infrared, computed tomography method has potential to provide assurance of structural integrity for airframes, doublers and pipelines.

Affordable asphalt-covered bridge deck rehabilitation requires an NDI method to accurately estimate the amount of deteriorated concrete from delaminations, which result from corrosion of the steel reinforcing bars, placed two inches beneath the surface of the concrete. We plan to conduct bridge deck demonstrations from a moving vehicle, for Phase 2 of the feasibility study. This is a logical extension of the investigation we successfully completed for Phase 1, e.g., by mapping the synthetic delaminations under asphalt-covered concrete slabs. These demonstrations are expected to estimate the amount of deteriorated concrete impairing the deck integrity. Potential longterm benefits are affordable, and reliable, rehabilitation for bridge decks.

\subsection{ACKNOWLEDGMENTS}

This work was performed by LLNL under the auspices of DOE contract number W-7405-ENG-48. We acknowledge support from the FAA Aging Aircraft Non-Destructive Inspection R\&D Program, Interagency Agreement DTFA03-92-A-00007 and Federal Highway Administration (FHWA Order Number DTFH61-93-Y-00145. We are grateful for the loan of the Bales Scientific Inc. uniform flashlamp heating source, the Rockwell 0.040-inch and 0.125-inch graded-thickness reference standards developed by Steve James, the F-15 corroded wing box which we used as a reference standard from Owen Manning at Northrop, and the reference panels from Jeff Thompson at Boeing. We acknowledge the helpful technical discussions, ultrasonic thickness-gauge measurements and support of the Boeing Commercial Airplane Group.

\subsection{REFERENCES}

1. Spicer, J. W. M., W. D. Kerns, L. C. Aamodt, R. Osiander and J. C. Murphy, "Time-Resolved Infrared Radiometry (TRIR) using a Focalplane Array for Characterizations of Hidden Corrosion", Proceedings of SPIE Conference 1933: Thermosense XV Ed. Lee R. Allen, Orlando FL p. 148, 1993.

2. Favro, L. D., P. K. Kuo, R. L. Thomas, T. Ahmed and Y. X. Wang, "Thermal wave imaging of corrosion and disbonds in aircraft structures" in Proceedings of SPIE Conference 2001: Nondestructive Inspection of Aging Aircraft. Ed. Michael T. Valley, Nancy K. Del Grande and Albert S. Kobayashi, San Diego CA, 1993.

3. Selman, John J. and J. Ted Miller, "Evaluation of a prototype thermal wave imaging system for nondestructive evaluation of composite and aluminum aerospace structures", Proceedings of SPIE Conference 1933: Thermosense XV Ed. Lee R. Allen, Orlando FL p. 178, 1993.

4. Syed, Hazari I., and K. Elliott Cramer, "Corrosion Detection in Aircraft Skin", Proceedings of SPIE Conference 1933: Thermosense XV, Ed. Lee R. Allen, Orlando FL p. 160, 1993.

5. Vavilov, V. P. and X. Maldague, "Dynamic thermal tomography: a new promise in the IR thermography of solids", Proceedings of SPIE Conference 1682: Thermosense XIV Ed. Jan K. Eklund, Orlando FL p. 194, 1992.

6. Alcott, John, "An Investigation of Nondestructive Inspection of Nondestructive Inspection Equipment: Detecting Hidden Corrosion on USAF Aircraft" in Materials Evaluation, American Society for Nondestructive Testing, Jan., 1994.

7. Del Grande, N. K., K. W. Dolan, P. F. Durbin and D. E. Perkins, "Emissivity-Corrected Infrared Method for Imaging Anomalous Structural Heat Flows", patent release confirmed, issue date scheduled for Aug. 1995.

8. Del Grande, N. K., and P. F. Durbin, "Mapping hidden aircraft defects with dual-band infrared computed tomography" in Proceedings of SPIE Conference 2455: Nondestructive Evaluation of Aging Aircraft, Airports, Aerospace Hardware, and Materials.Ed. Tobey Cordell, Oakland CA, June 6-8, 1995.

9. Durbin, P.F., and N. K. Del Grande, "Using emissivity-conrected thermal maps to locate deep structural defects in concrete bridge decks" in Proceedings of SPIE Conference 2456: Nondestructive Evaluation of Aging Bridges and Highways. Ed. Steve Chase, Oakland CA, pp. 250-261, June 6-8, 1995. 
10. Del Grande, Nancy K., Philip F. Durbin and Michael R. Gorvad, "Infrared Computed Tomography" in Nondestructive Evaluation Thrust Area Report FY93, Engineering Research Development and Technology, Ed. Harry E. Martz, UCRL-ID115668, May 1994.

11. Del Grande, Nancy K., and Philip F. Durbin, "Multi-use applications of dual-band infrared (DBIR) thermal imaging for detecting structural defects" in Proceedings of SPIE Conference 2217: Aerial Surveillance Sensing Including Obscured and Underground Object Detection, Ed. Ivan Cindrich, Nancy K. Del Grande, Sankaran Gowrinathan, Peter Johnson and James F. Shanley, Orlando Fl Apr. 1994.

12. Del Grande, N. K., and P. F. Durbin, "Dual-Band Infrared Imaging to Detect Corrosion Damage Within Airframes and Concrete Structures", in Proceedings of SPIE Thermosense XVI, International Conference on Thermal Sensing and Imaging and Diagnostic Applications, Ed. John Snell, Orlando FL, Apr. 1994.

13. Durbin, Philip and Nancy Del Grande, "Dual-band Infrared Imaging For Concrete Bridge Deck Inspection", Proceedings of Structural Materials Technology-An NDT Conference, Atlantic City NJ, Feb. 1994.

14. Del Grande, N. K., "Dual Band Infrared Imaging for Quantitative Corrosion Detection in Aging Aircraft", Proceedings of the American Society for Nondestructive Testing (ASNT) Meeting, Nov. 1993.

15. Del Grande, N. K., K. W. Dolan, P. F. Durbin, M. R. Gorvad and A. B. Shapiro, "Dual-Band Infrared (DBIR) Imaging Inspections of Boeing 737 and KC-135 Aircraft Panels", UCRL Report: Interagency Agreement DTFA03-92-A-0007(1993). Original July, 1993. Revised November, 1993.

16. Del Grande, N. K., K. W. Dolan, P. F. Durbin, M. R. Gorvad and A. B. Shapiro, "Dynamic thermal tomography for nondestructive inspection of aging aircraft" in Proceedings of SPIE Conference 2001: Nondestructive Inspection of Aging Aircraft. Ed. Michael T. Valley, Nancy K. Del Grande and Albert S. Kobayashi, San Diego CA July,1993.

17. Del Grande, N. K., K. W. Dolan, P. F. Durbin, M. R. Gorvad, B. T. Kornblum, D. E. Perkins, D. J. Schneberk and A. B. Shapiro, "Three-Dimensional Dynamic Thermal Imaging of Structural Flaws by Dual-band Infrared Computed Tomography" in Proceedings of SPIE Conference 1942: Underground and Obscured Object Imaging and Detection, Ed. Nancy Del Grande, Ivan Cindrich and Peter Johnson, Orlando FL Apr. 1993.

18. LeSchack, L. A., and N. K. Del Grande, "A Dual-Wavelength Thermal Infrared Scanner As A Potential Airborne Geophysical Exploration Tool", Geophysics 41, p. 1318, 1976.

19. Grinzato, E. G., C. Bressan, P. G. Bison, A. Mazzoldi, P. Baggio, C. Bonacina, "Evaluation of moisture content in porous material by dynamic energy balance", in Proceedings oof SPIE Conference 1682: Thermosense XIV, Ed. Jan K. Eklund, Orlando FL p. 213, 1992.

20. Ph. M. Delpech, D. M. Boscher, F. Lepoutre, A. A. Deom and D. L. Balageas, "Quantitative nondestructive evaluation of carbon-carbon composites by pulsed infrared thermography", in Review of Progress in Quantitative Nondestructive Evaluation, 12B Ed. by Donald O. Thompson and Dale E. Chimenti, Plenum Press, New York and London, p. 1297, 1993.

21. H. S. Carslaw and J. C. Jaeger, Conduction of Heat in Solids, 2nd Edition, Oxford Univ. Pr., London, pp. 101, 112 and 259, 1980. 
Temperature Map at .43 Sec. with $1^{\circ}$ Rise $=12.5 \%$ Metal Loss

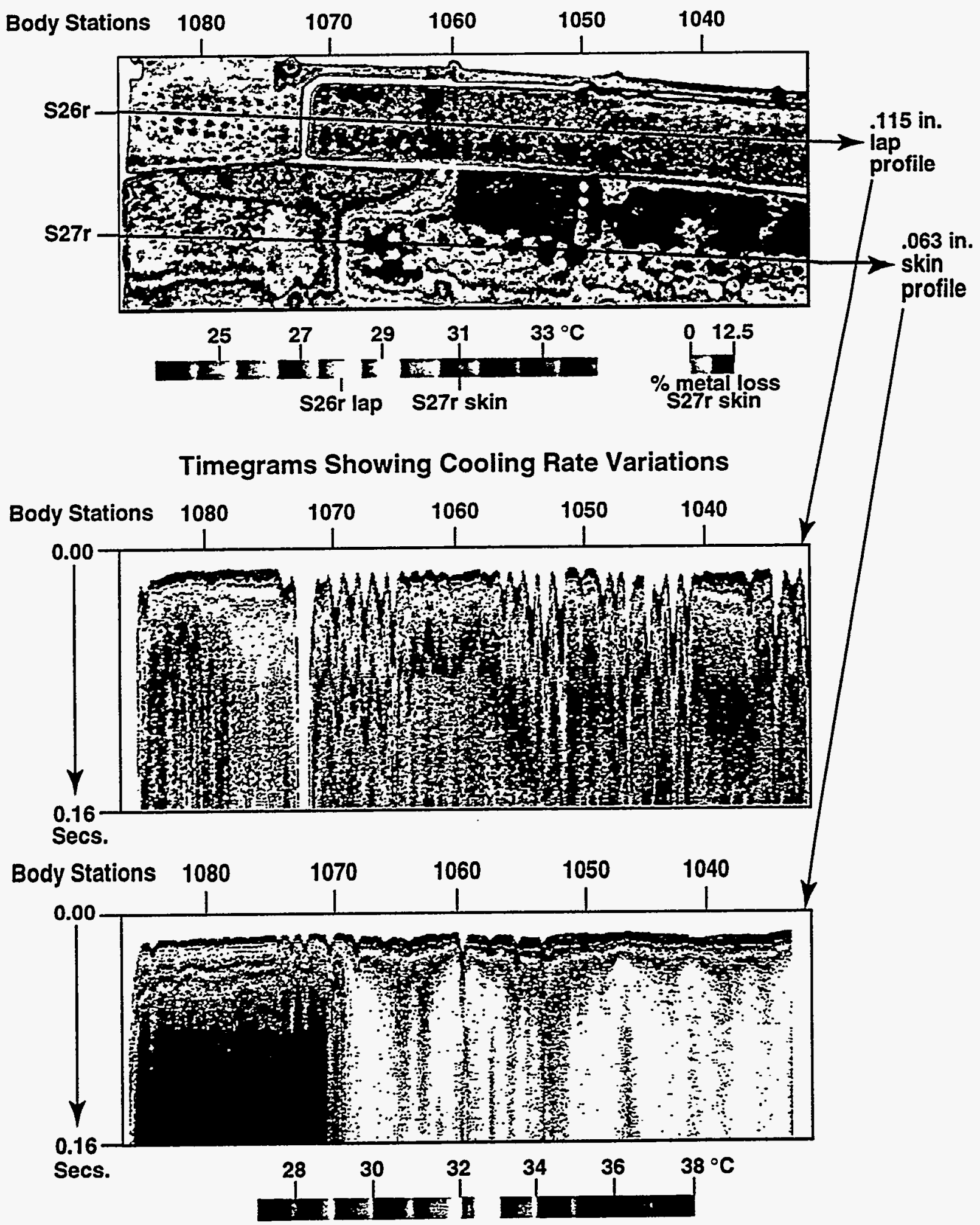

Figure 1. The Boeing 727 fuselage temperature map and timegrams. Note surface temperature rises of $0.8^{\circ} \mathrm{C}$ along S $27 \mathrm{r}$ skin profile which correspond to a $10 \%$ metal loss. 


\section{Temperature Maps}
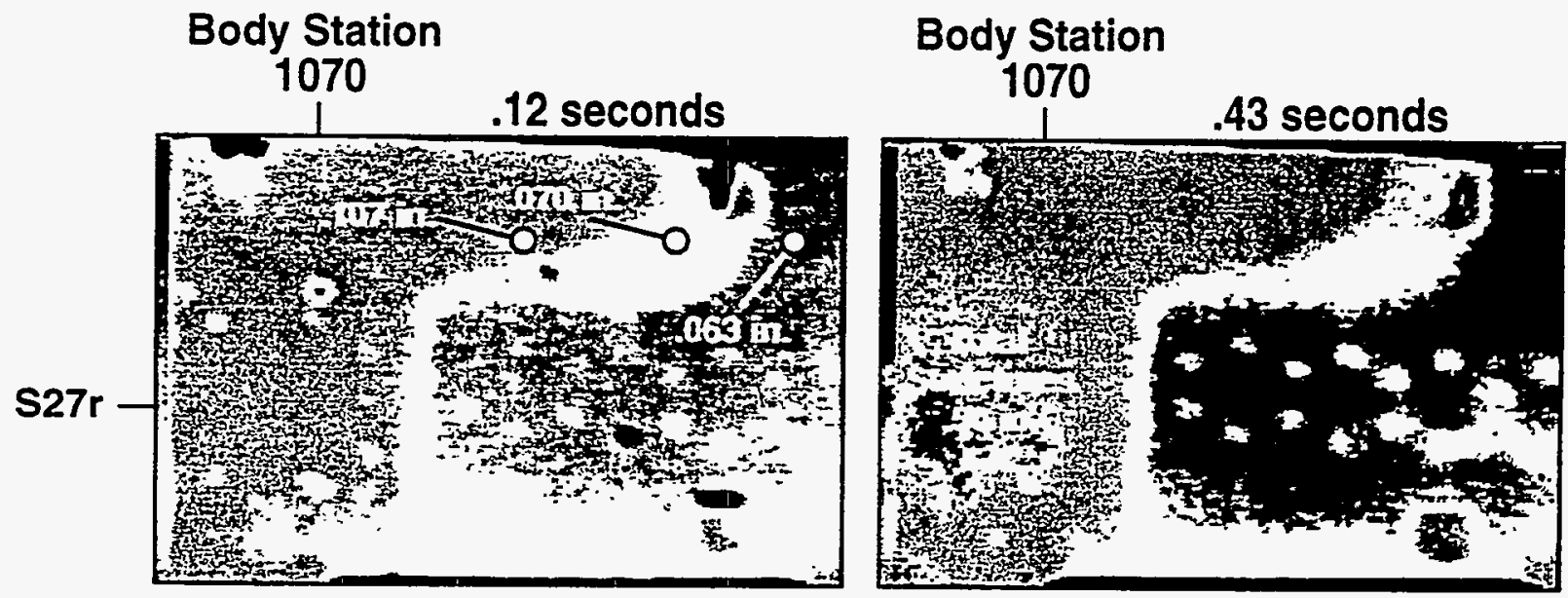

I

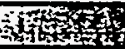

Low

Temperature

High

\section{Thermal Inertia Maps}
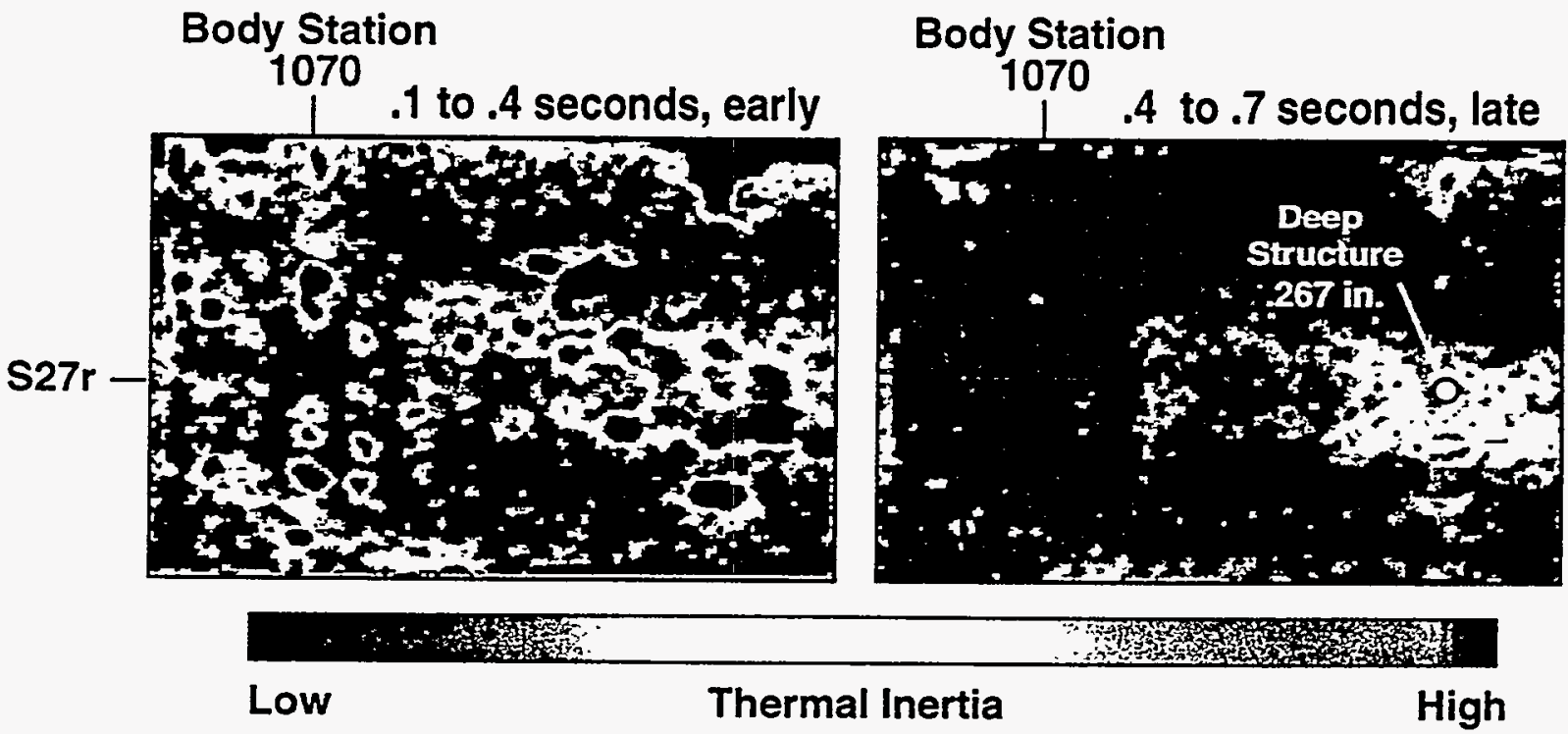

Figure 2. Temperature maps highlight outer skin thicknesses of .063 to .107 inches. Thermal inertia maps show shallow riveted skins at early times and deeper structures at late times. 


\section{Concrete slab defect maps derived from dual-band infrared images}
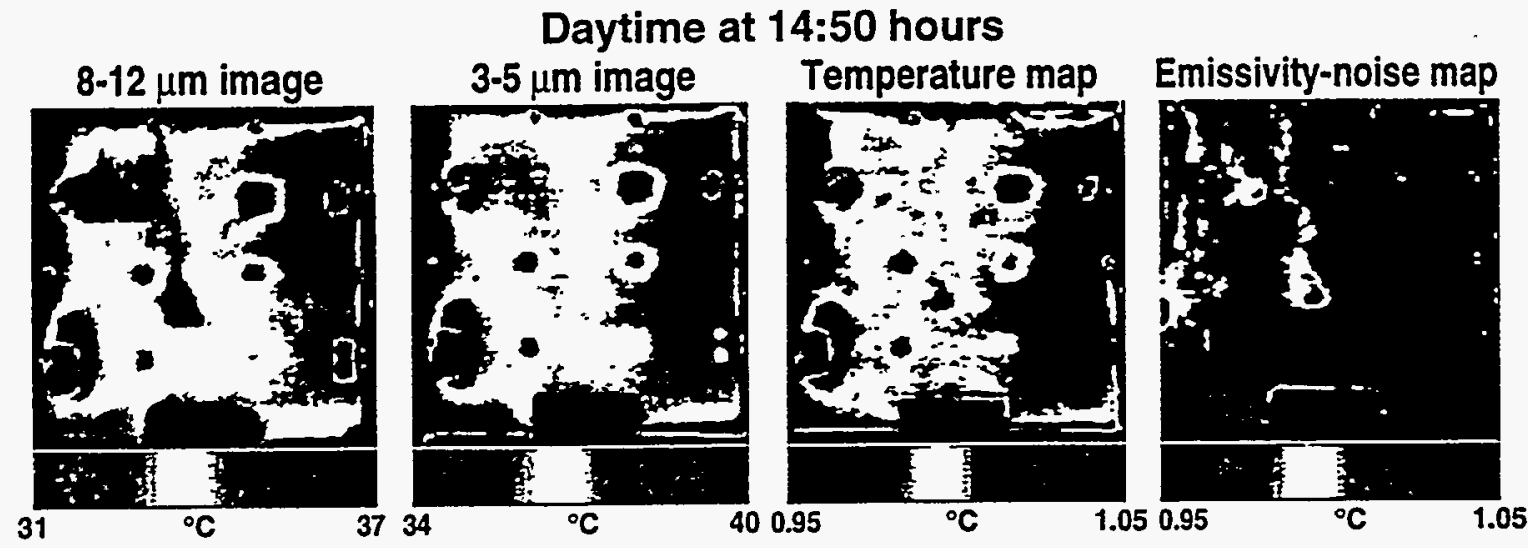

Map of surface object and hidden defect sites
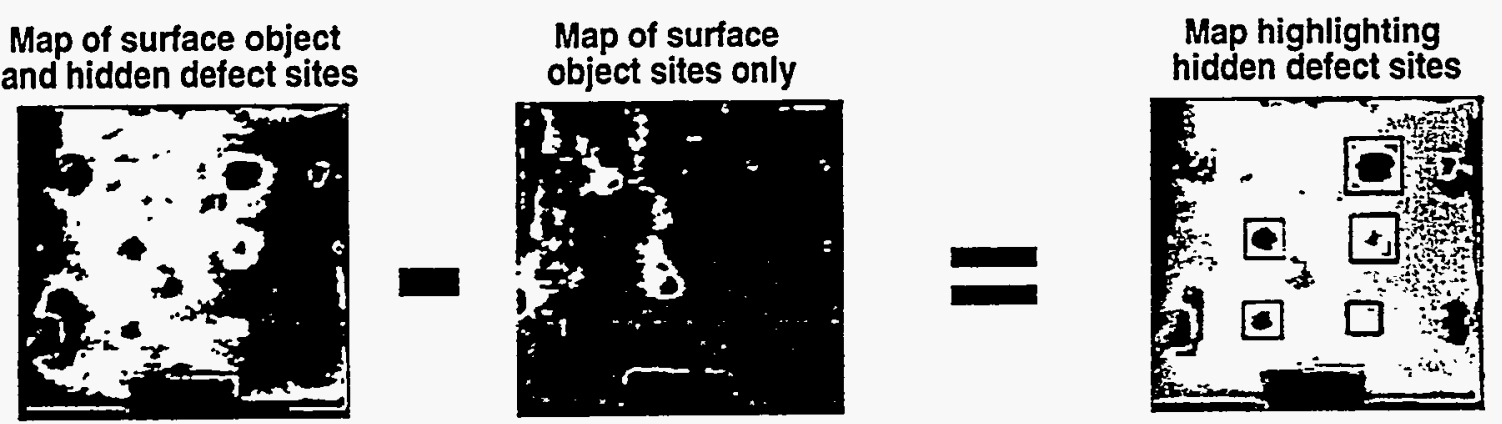

Nighttime at 06:02 hours
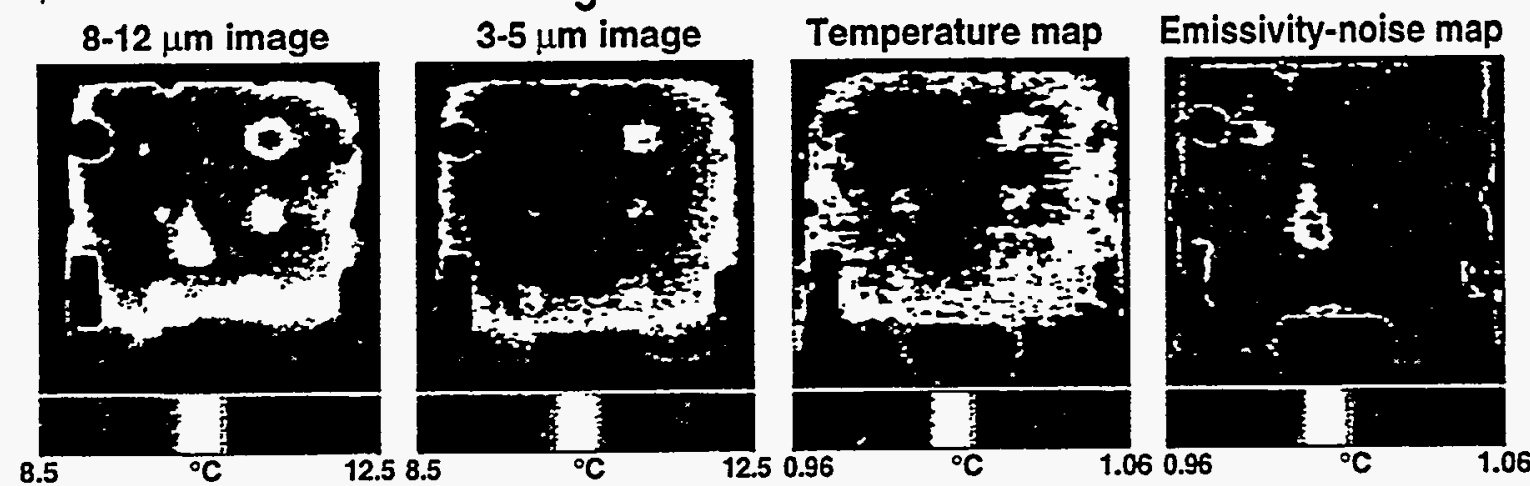

Map of surface object and hidden defect sites
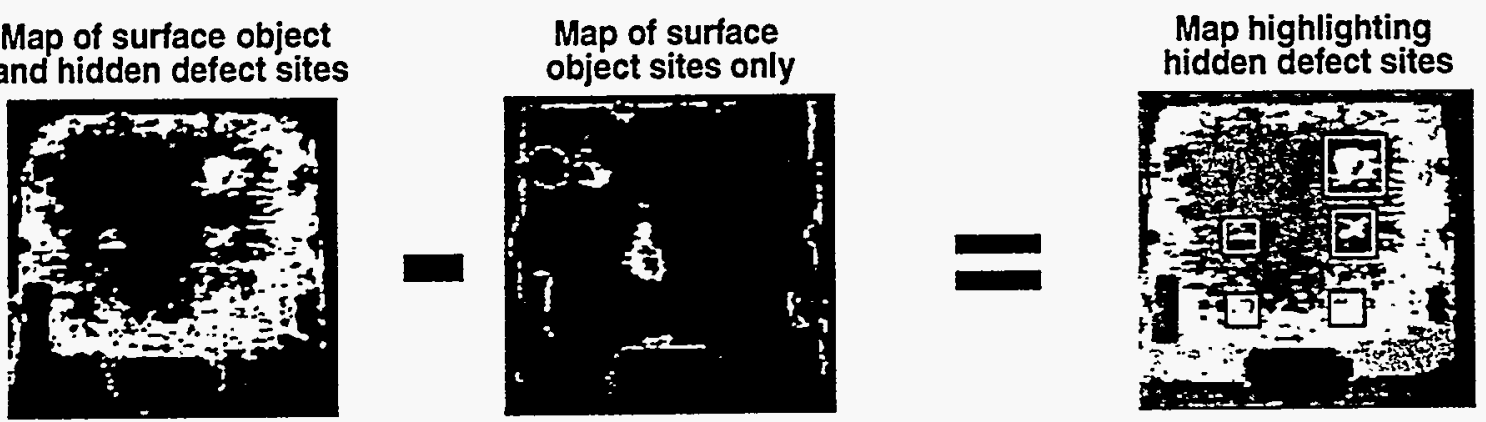

Figure 3. Dual-band (two color) IR temperature and emissivity-noise maps are used to locate sites with 2-inch deep defects in concrete slabs and remove sites with surface emissivity-noise. 


\section{Asphalt-concrete slab defect maps with corrections for uneven asphalt compaction}

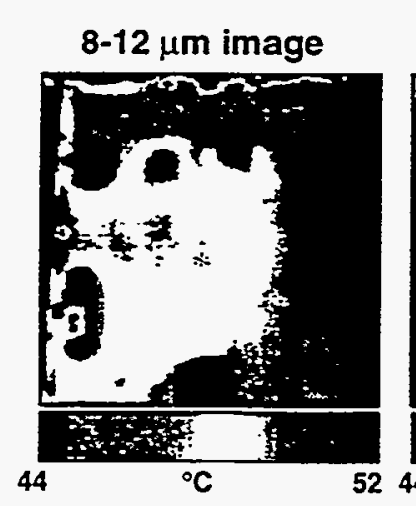

Map of surface object and hidden defect sites

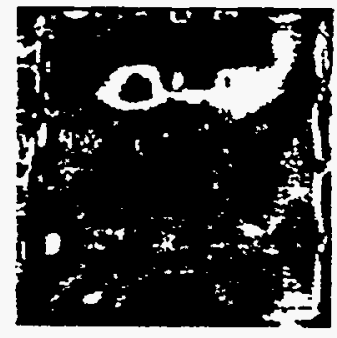

8-12 $\mu \mathrm{m}$ image

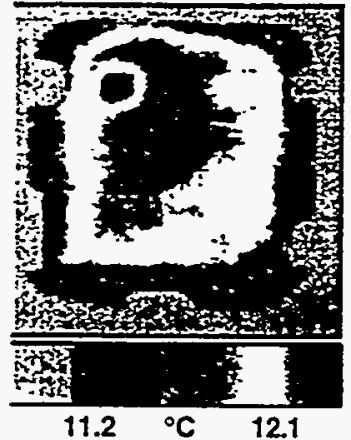

Map of surface object and hidden defect sites

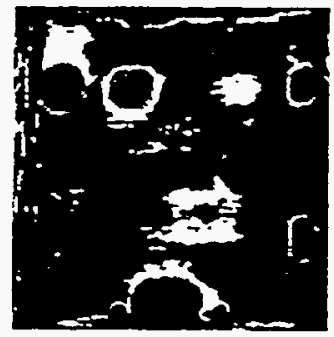

Daytime at 14:36 hours
3-5 $\mu \mathrm{m}$ image

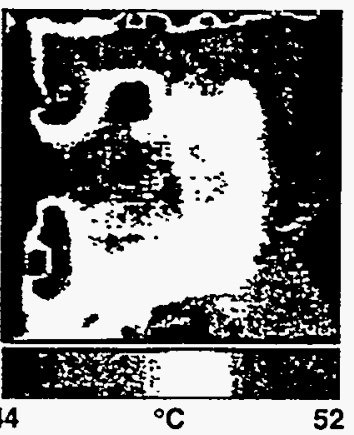

Temperature map*

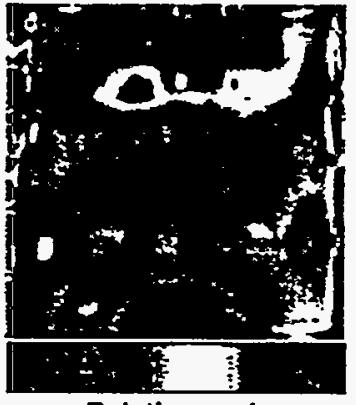

Relative scale

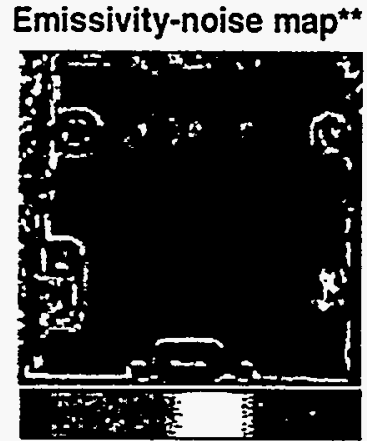

Relative scale

Map highlighting hidden defect sites

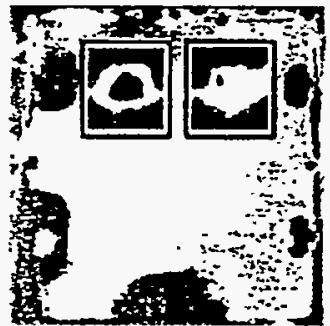
object sites only
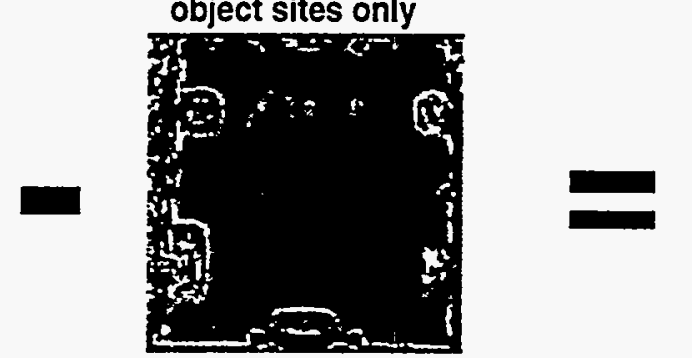

Nighttime at 06:17 hours

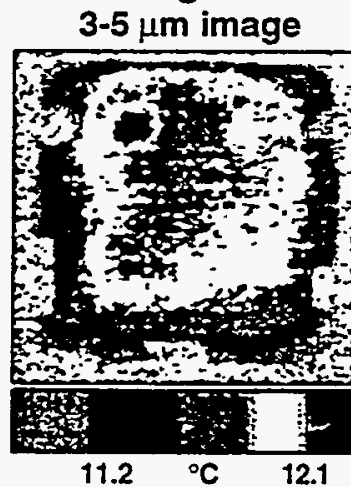

Temperature map*
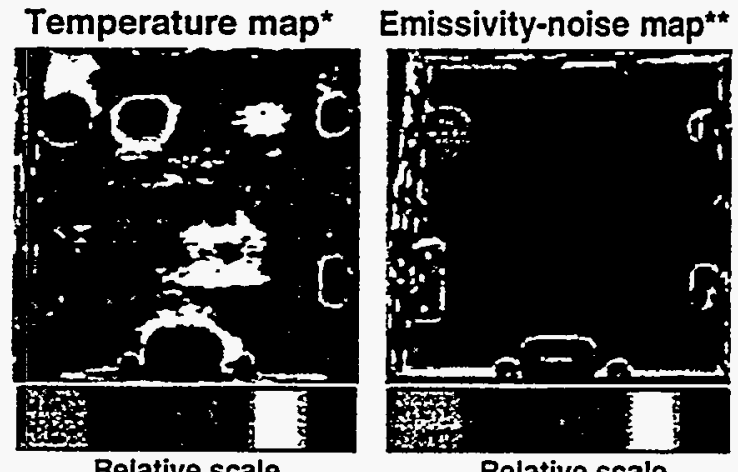

Relative scale

Relative scale

Map highlighting hidden defect sites
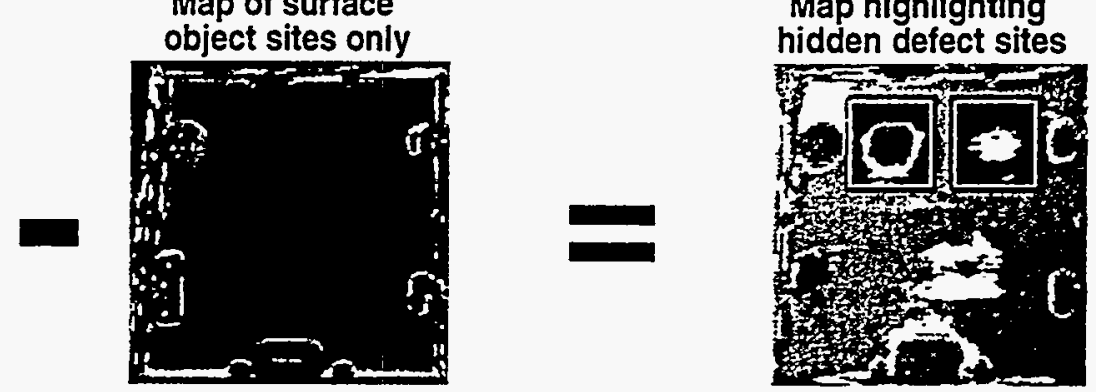

- Corrections made to remove asphalt-layer thermal noise.

- Filter used to enhance surface objects.

Figure 4. Dual-band (two color) IR temperature and emissivity-noise maps are used to locate sites with 4-inch deep defects in asphalt-concrete slabs and remove sites with surface objects. 